NPA (2000) Brief Report on Suicides in 1999. Tokyo: NPA (in Japanese).

NPA (200I) Brief Report on Suicides in 2000. Tokyo: NPA (in Japanese).

NPA (2002) Brief Report on Suicides in 2001. Tokyo: NPA (in Japanese).

Rutz, W., Von Knorring, L. \& Walinder J. (1992) Long-term effects of an educational program for general practitioners given by the Swedish Committee for the Prevention and Treatment of Depression. Acta Psychiatrica Scandinavica, 85, 83-88.

\section{Further reading}

Fushimi, M., Sugawara, J. \& Shimizu, T. (2005) Suicide patterns and characteristics in Akita, Japan. Psychiatry and Clinical Neurosciences, 59, 296-302.

\title{
Suicide trends and characteristics in Brazil
}

\section{Carolina de Mello-Santos, ${ }^{1}$ José Manoel Bertolote ${ }^{2}$ and Yuan-Pang Wang ${ }^{1,3}$}

'Psychiatry Institute of the Universidade de São Paulo School of Medicine, São Paulo, Brazil, email caro_mello@hotmail.com

${ }^{2}$ World Health Organization Team on Management of Mental and Brain Disorders

${ }^{3}$ Santo Amaro School of Medicine, UNISA, São Paulo, Brazil

razil is the largest and most populous country in South America (in 2002 the population was approximately 175 million). Although life expectancy in Brazil has increased, suicide and other forms of injury-related mortality, such as homicide and accident, have increased as a proportion of overall mortality (Oswaldo Cruz Foundation, 1984; Brazil Ministry of Health, 200I). The suicide rate in Brazil (3.0-4.0 per 100000 inhabitants) is not considered high in global terms (World Health Organization, 1999). Nevertheless, it has followed the world tendency towards growth: during 1980-2000, the suicide rate in Brazil increased by $21 \%$. Elderly people present the highest suicide rates in absolute numbers, but the alarming finding in the Brazilian data is that the youth population is increasingly dying by suicide (Mello-Santos et al, 2005). This statistic partially confirms a forecast by Diekstra \& Guilbinat (1993) that the number of deaths by suicide would dramatically increase over the next decades, mainly in developing countries, including Latin America. In these regions, socio-economic factors (such as an increase in divorce and unemployment and a decrease in religiosity) increase the risk of self-harm. We discuss the reasons for the low suicide rate in Brazil and highlight the socio-economic factors affecting its increase among the youth population in particular.

\section{Low suicide rate in Brazil: fact or artefact?}

It is important to determine whether there was an actual increase in suicide rates in Brazil or whether it represents only a methodological artefact arising from the improvement in data collection at national level. The tendency for not all deaths to be notified in Brazil is common to other Latin American countries as well; the problem is compounded by the authorities' disregard (Grossi \& Vassan, 2002). The Brazilian Mortality Information System, operated by the Ministry of Health, may be capable of tracing only about $80 \%$ of total deaths in Brazil, since $20 \%$ of deaths are not registered (Mello-Jorge et al, 1997).

Some peculiarities of the Brazilian health system may have affected the national statistics. One methodological problem of registering death is the difficulty of distinguishing suicide from other violent deaths, such as homicide and accident. Frequently, coroners do not record the basic cause of death on the death certificate, but instead explain only the nature of the lesion. In Brazil, suicide cases are registered according to the classifications in the 'external causes' section of ICD-10 (World Health Organization, 1992), which classifies lethal events not arising from biological diseases as: those resulting from violence, those resulting from fatal accidents, and suicide. This procedure hampers the gathering of conclusive data on the nature of the death, such as the non-accidental cases (e.g. exogenous intoxication in the case of alcohol-related car accidents). Brazilian authorities are more concerned with the registering of accidents and homicides than with the accuracy of suicide statistics, as homicide is the largest single cause of death in Brazil. During 1980-2002, the homicide rate in Brazil more than doubled, from II.4 per 100000 population to 28.4 (Gawryszewski \& Mercy, 2004).

Relatives and even the authorities often conceal the suicide for fear of judicial disputes or retaliation. There is a social prejudice against suicide and this results in non-disclosure (Mello-Jorge, 1988; Souza, 1991).

On the other hand, obtaining access to the means of suicide is easy in Brazil. The sale of psychotropics on the black market, the non-regulated and illegal carrying of guns, the ambiguous policy in relation to alcoholism, and the sale of caustic soda and rat poison in supermarkets are some examples. These
Elderly people

present the

highest suicide

rates in absolute

numbers, but the alarming finding in

the Brazilian data

is that the youth

population is

increasingly dying

by suicide.

Brazilian

authorities

are more

concerned with

the registering

of accidents

and homicides

than with the

accuracy of

suicide statistics,

as homicide is

the largest single

cause of death in

Brazil. 
are the major means of attempting suicide. Pesticides are commonly used in rural areas. The recent disarmament campaign, the withdrawal of inflammable products from supermarket shelves, a prohibition of the sale of some types of rat poison and stricter pesticide sales regulations reflect increasing concern. However, the Brazilian government still has not adequately tackled the recent increase in suicide rates through control of the means of suicide.

\section{Suicide among Brazilian youth: the role of socio-economic factors}

\section{Recent data indicate that Brazilian youths are dying more from violent causes than from biological ones.}

The male:female ratio for suicide is $3: 1$, which is consistent with the findings of international studies....

However, this ratio is reversed when we study suicide attempts: women are three times more inclined to attempt suicide than men.
The significant increase in suicide among Brazilian youths (those aged 15-24 years) is in line with a world tendency, in which the majority of suicides occur in the population aged 5-44 years (Bertolote \& Fleischmann, 2002). From 1980 to 2000, the suicide rate in this age-group increased $1000 \%$ in Brazil. Female suicide within the same age-group increased only $400 \%$, while the male increase was about 2000\% (Mello-Santos et al, 2005). Our own data for the city of São Paulo, the largest and most important Brazilian city, can be used to illustrate the national findings: from 1996 to 2000, 66\% of all suicides were by persons aged 5-44 years. Recent data indicate that Brazilian youths are dying more from violent causes than from biological ones. In nine Brazilian capitals surveyed, Souza et al (2002) noted a 27.6\% increase between 1979 and 1998 in deaths due to external causes among individuals aged 15-24 years. Suicide was ranked sixth among the external causes.

The analysis of the young people who have died by suicide reveals a population in crisis. The common characteristics are being male, single and a non-specialised worker with low educational attainment (Souza et al, 2002). These factors, together with the highly competitive market economy, limited employment opportunities and low governmental incentives, further combined with professional and economic instability, make the young population vulnerable. Accordingly, these factors are related to feelings of hopelessness among the younger generation, which encourages their suicidal behaviour. However, more studies are necessary to clarify the relationship between socio-economic factors and suicide among Brazilian youths.

\section{Suicide methods and gender}

The male:female ratio for suicide is $3: 1$, which is consistent with the findings of international studies (Bertolote \& Fleischmann, 2002). However, this ratio is reversed when we study suicide attempts: women are three times more inclined to attempt suicide than men (Teixeira \& Villar Luis, 1997).

The difference in gender also reflects the lethality of the methods chosen. Women opt for poisoning or overdose, whereas men look to violent and more lethal methods, such as hanging and the use of firearms (Teixeira \& Villar Luis, 1997) - the two most common methods in Brazil (Souza et al, 2002; Grossi \& Vassan, 2002). In Brazil, two important suicide methods, mainly used by women, should be mentioned: the use of methyl alcohol for self-immolation (Marchesan et al, 1997; Souza et al, 1998) and the ingestion of carbamate (a rat poison) (Lima \& Reis, 1995). Men die by suicide typically because they seek a drastic solution to a personal problem; women generally attempt suicide in an attempt to improve adverse conditions (Teixeira \& Villar Luis, 1997).

Information on family problems, religiosity and divorce are not available in the routinely collected data for suicide.

\section{Conclusion}

Even though their reliability can be questioned, the Brazilian data on suicide rates allow the identification of risk groups among the general population. The increase in the youth suicide rate is a worldwide phenomenon, not exclusive to Brazil. In spite of the low suicide rates among Brazilian youths, its steady increase over the last two decades is a reason for concern. The young population, who have few opportunities, are vulnerable to socio-economic factors. Preventive strategies directed at this population should be implemented in order to reverse this trend. Intervention studies with high-risk populations are tasks for Brazilian researchers and a challenge for the public health authorities.

\section{References}

Bertolote, J. M. \& Fleischmann, A. (2002) A global perspective on the epidemiology of suicide. Suicidologi, 7, 6-7.

Brazil Ministry of Health (200I) Brazilian Health Statistics Yearbook. Available at http://portal.saude.gov.br/portal/saude.

Diekstra, R. F. W. \& Guilbinat, W. (1993) The epidemiology of suicidal behaviour: a review of three continents. World Health Statistics Quarterly, 46, 52-68.

Gawryszewski, V. P. \& Mercy, J. A. (2004) Homicide trends and characteristics Brazil, 1980-2002. Morbidity and Mortality Weekly Report, 53, 169-171.

Grossi, R. \& Vassan, G. A. (2002) Mortalidade por suicídio no município de Maringá, Paraná. [Suicide mortality in Maringá City, Paraná.] Jornal Brasileiro de Psiquiatria, 510, 101-1 | I.

Lima, J. S. \& Reis, C. A. (1995) Poisoning due to illegal use of carbamates as a rodenticide in Rio de Janeiro. Journal of Toxicology. Clinical Toxicology, 33, 687-690.

Marchesan, W. G., da Silva, F. F., Canalli, J. E., et al (1997) Suicide attempt by burning in Brazil. Burns, 23, 270-27I.

Mello-Jorge, M. H. P. (1988) Investigação sobre a mortalidade por acidentes e violência na infância. [Mortality investigation of accidents and infant mortality.] PhD thesis, Faculdade de Saúde Pública da USP.

Mello-Jorge, M. H. P., Gawryszewski, V. P. \& Latorre, M. R. D. O. (1997) Análise dos dados de mortalidade, São Paulo. [Data analysis of mortality, São Paulo.] Revista de Saude Publica, 31 (suppl. 4), 5-25.

Mello-Santos, C., Bertolote, J. M. \& Wang, Y. P. (2005) Epidemiology of suicide in Brazil (1980-2000): characterization of age and gender rates of suicide. Revista Brasileira de Psiquiatria, 27, $13 \mid-134$.

Oswaldo Cruz Foundation (1984) Mortality in Brazilian capitals 1930-1980. Reunion, Analysis, Diffusion of Health Information/ Data, 3, I-8. 
Souza, D. A., Marchesan, W. G. \& Greene, L. J. (1998) Epidemiological data and mortality rate of patients hospitalized with burns in Brazil. Burns, 24, 433-438.

Souza, E. R. (199|) Violência velada e revelada: estudo epidemiológico da mortalidade por causas externas em Duque de Caxias - R]. [Concealed and revealed violence: epidemiological study of external causes of mortality in Duque de Caxias - Riojaneiro.] Masters dissertation, Escola Nacional de Saúde Pública, Rio de Janeiro.

Souza, E. R., Minayo, M. C. S. \& Malaquias, J. (2002) Suicídio de jovens nas principais capitais do Brasil, Rio de Janeiro. [Youth suicide in major Brazilian capitals, Rio de Janeiro.] Cadernos de Saúde Pública, 18, 673-683.
Teixeira, A. M. F. \& Villar Luis, M. A. ( 1997) Distúrbios psiquiátricos, tentativas de suicídio, lesões e envenenamento em adolescentes atendidos em uma unidade de emergência, Ribeirão Preto, São Paulo, 1988-1993. [Mental disorder, suicide attempt, lesions and assistance in an emergency unit for youth poisoning, Riberão Preto, São Paulo, 1988-1993.] Cadernos de Saúde Pública, I3 517-525.

World Health Organization (1992) International Classification of Diseases and Related Health Problems (I0th revision) (ICD-I0). Geneva: WHO.

World Health Organization (1999) Figures and Facts About Suicide (doc. WHO/MNH/MBD/99. I). Geneva: WHO.

\section{Perspectives on suicide in Africa}

\section{N. K. Ndosi MD PhD}

Associate Professor, Department of Psychiatry, MUCHS PO Box 65051, Dar es Salaam, Tanzania, email nkndosi@hotmail.com

\begin{abstract}
uicide is a serious worldwide health problem, particularly among youths. It is defined as the intentional act of killing oneself. Analytically, the suicidal act entails: the wish to kill, the wish to be killed and the wish to die. People who die by suicide know what they are doing and are aware of the consequences of their actions. A completed suicidal act is a complex phenomenon associated with psychological, biological and social factors. It follows severe exhaustion under a continuing assault of stressors when the suicidal individual is no longer able to cope with and to restore homeostasis. In order to categorise a case as a suicide, legal authorities demand unequivocal evidence of intent.
\end{abstract}

\section{Common determinants of suicide}

In many traditional African cultures people fear death by suicide and it is one of the strongest taboos. In East Africa suicide is a terrible event for family and close friends (Swift, 1977, p. I18). Rates of suicides were considered to be low in Africa as a result of both a paucity of depressive conditions and frequent communal clashes that diverted aggression away from the self and towards others (Elliott, 200 I). This view is no longer tenable, however. Depression in Africans is not readily recognised, as it tends to present with somatisation, rather than feelings of guilt and self-reproach, unlike in Western cultures (Morgan, 1979).

Although there is rather little information on the causes of suicide in sub-Saharan Africa, there are indicators that the rates are rising, particularly among young people, and that the majority of cases result from overwhelming social factors (Lister \& Wilson, 1990; Nwosu \& Odesamni, 200 I; Ndosi et al, 2004).

Rapid urbanisation in Africa is undermining the prevailing networks for social support and causing the social alienation of individuals. The ensuing diverse psychosocial pathologies increasingly predispose people to suicide (Ndosi, 2005). Young people experience more stress in relation to their as yet unmet expectations and demands from their governments. When emotionally overwhelmed, in the absence of people to confide in, they tend to develop suicidal thoughts.

Continuing poverty among Africans threatens the very fabric of existence. Some 340 million Africans live on less than US\$I per day (Heggenhougen \& Lugalla, 2005, pp. 29I-300). Extreme poverty destabilises lives, crushes self-esteem and creates despair, and this can lead to self-harm. Poverty marginalises, stigmatises and erodes human decency and leads to dependence and powerlessness. Unemployment and underemployment (as petty traders or lowly paid workers) subject young adults to hardships which enhance ruminations of self-destruction.

The gender identity of the majority of sub-Saharan women is deeply embedded in a cultural context of male dominance. Many women are thus pushed into defeat and helplessness, which makes them vulnerable. Conjugal relationships are fraught with jealousies, grief, feelings of abandonment and fear of contracting sexually transmitted diseases (Kabeer, 1993). Culturally, men have the right to discipline their wives, and wifebeating is widespread. Anger, shame and despair attain overwhelming levels, and suicide can be an expression of intolerable distress.

Despite the paucity of data, clinical observations indicate that a considerable proportion of young females who have become pregnant unexpectedly attempt and complete suicide when they are abandoned by their male partners (Ndosi \& Waziri, 1997; Ndosi et al, 2004).

In clinical practice, about $90 \%$ of people who die by suicide suffer from an underlying psychiatric disorder (Ndosi et al, 2004). The risk of patients with a mental illness killing themselves is 3-12 times greater than that of people without psychiatric illness. In particular, the lack of dependable social support for those with schizophrenia can make them feel lonely and unwanted. They continue to suffer from the stigma attached to mental illness in their communities,
Depression in

Africans is not readily recognised, as it tends to present with somatisation, rather than feelings of guilt and self-reproach, unlike in Western cultures. 